\title{
Giving Suggestion Techniques to Build Communicative Interaction in Academic Articles
}

\author{
Agung Budi Kurniawan ${ }^{1}$, Warsono $^{2}$, Djoko Sutopo ${ }^{3}$, Sri Wuli Fitriati ${ }^{4}$ \\ (agungbudi430@yahoo.co.id ${ }^{1}$,warsono1103@gmail.com², djoko.sutopo@mail.unnes.ac.id ${ }^{3}$, \\ SriWuli.Fitriati@mail.unnes.ac.id ${ }^{4}$ ) \\ STKIP PGRI Pacitan, Indonesia \\ Graduate School, Universitas Negeri Semarang, Indonesia, ${ }^{2,3,4}$
}

\begin{abstract}
Writing for publication is to present the research process and result, and build communicative interaction with readers. The writers need to gain the readers' high attention. The objective of this study was to find out the implications and benefits of the techniques of giving suggestion to build communicative interaction in five articles in ELT. The articles were selected through purposive sampling technique. Then, it was analyzed by using classifying technique and involving the Interpersonal meaning concept. The findings show that indirect suggestion is the most effective technique to build the communicative interaction. The writers could suggest readers indirectly to agree with the ideas, hypothesis, method, even the finding and analysis. The benefit of the findings was that the suggestion technique could be a hedge to avoid getting strong and negative impression of claiming truth. It also helped the writers' information become soft and understandable.
\end{abstract}

Keywords: Suggestion, Communicative, Academic, Articles

\section{Introduction}

The publication of academic articles or papers for college students becomes more familiar in the present day. In fact, the writing process of academic articles for publication needs specific criteria and strategy. Meanwhile, we need to view the characteristic of academic article, writing for publication, persuasive writing, and the scope of discourse study that cover the suggestion technique.

Academic writing is a writing activity that needs to follow the academic and scientific rule. It is not about free writing. The skill of academic writing was the ability to promote hypothesis and conclusion, and organize the text [1]. Then, the cognitive strategy could be recognized as part of academic writing [2]. It also needs to be understood that the important aspect of academic writing was making use of the ideas being able to be understood by readers [3]. In addition, academic writing was not only about formal genre mastery, but also about how critically the writer to present the information [4]. In this term, academic writing was not only about proposing the information, but also about how to propose it. It requires technique, plan and strategy. It was the result of theory mastery and practice. Academic writing concept needs to be understood by ELT and all college department students to support their publication.

Students or writers also need to recognize the concept of writing for publication. It was not only about developing the ideas, but also about how the writing could be accepted by 
readers. There is one concept that the papers for publication must be written for a specific audience [5]. It was also concluded that the quality of students' writing determines to be accepted in academia [6]. On the other hand, it is the concept of academic writing for communication with editors, reviewers, and other scholar and objected to convey the core of the message [7]. Writing for publication was the field application and implication of academic writing. In the writing for publication, the students or writers must carry out good endeavor so that the written text could be accepted by the publisher, editor, and readers. It needs the technique to build the communicative interaction for the written text.

One of the techniques was the persuasive writing. We need to proposed the hypothesis and recognize to whom our writing would be addressed [8]. In fact, distinguishing between strong and relevant argument revealed an issue [9]. Persuasive writing is an approach that could be applied for publication. The approach could make writers to be closer with the editor, reviewer, and readers, and get their attention.

In fact, one of the possible applications of the persuasive writing for publication is the suggestion technique based on the Discourse and Appraisal study. The concept of the discourse study is the study of transferring context in the text [10]. In addition, there is the evident of the successfulness of Appraisal study with genre analysis [11]. One of Appraisal materials that could be applied to support the persuasive writing for publication was suggestion [12].

Based on the background, the researchers studied the suggestion technique application in the five article publications. The research problem was "how are the implications and benefits of technique of giving suggestions to write academic articles?". The objective of this research was "to find out the implications and benefits of the technique of giving suggestion that makes the academic writing for publication become interactive".

\section{Method}

This research was conducted through qualitative design. This research viewed the research concept, problem, and object relied on how they work based on the human perception and understanding [13]. The perception and understanding proposed the evidences totally. The object was five articles in English Language Teaching or ELT study field. It was why called as the academic article. The objects were selected carefully by using purposive sampling technique. The instrument to collect and analyze the data comprised the laptop, dictionary, and list of lexical. In order to collect the data, this research applied the method of classifying each category in a schema of finding list. Then, they were analyzed by using the technique of coding the classified data, and then they were interpreted based on the evidence of the use.

\section{Results and Discussion}

It was found ten techniques of giving suggestion in the five articles or objects. Every finding represented one object or article. It was similar with the persuasive writing, but it was in the different approach of Interpersonal meaning. Every technique has different implications and benefits. The schema of the findings and discussion writing in the text was proposing the main finding and discussion of every strategy, and then it was followed by the elaboration of the wider implication. 
Variable strength was found as the first material exploration in the article or object 1 . After getting deep identification and analysis, the technique of giving suggestion was concluding the strength of the research variable to ensure reader not to get doubt. The application of the technique was carried out by reviewing and comparing the research and the previous study variable. The positive implication was that it did not decrease the previous study variable, but it explored its strength. The writers proposed the renewal of the strength simultaneously as the development sense. It avoids giving antithesis of the variable strengths. The benefit of this technique could avoid writers getting negative impression because they also appreciated the previous study variables very well. The other benefit was that it ensures the originality of the whole new concept in the similar boarder. The technique was compatible with one previous study that one of persuasive writing techniques was providing the fact, data statistic, and example in the body of the paragraph because it suggested the knowledge to readers [14]. The other previous study found students could construct their argumentative writing successfully by creating the graphic organizers and reviewing the scaffolded question [15]. The exploration of variable increased the possibility to ensure readers about the truthfulness of the research concept and findings.

The second technique still refers to the object article 1 . The second suggestion technique was to propose the theoretical framework which was short and coherence with the result of the previous studies and theoretical review. So, the quality of both the review determined the theoretical framework performance. The previous studies must be in line with the research topic or article first. It was recommended to choose the previous studies which are to discuss the similar problem and finding. One example when the author would like to suggest the English classroom practice, they cannot take the education management previous studies. It was about the coherence of the previous study topic with the suggestion material based on the research finding. The other aspect was the status of the authors and the publication year of the previous studies. Readers tend to get higher interest when the author of the previous studies was a famous expert. It also increased the credibility of the suggestion. Moreover, the expert authors usually write qualified paper that it also helps the article writers to discuss, compare, and give good suggestion. The year of publication was the additional point. It was recommended to review the previous studies that were published maximum seven years ago. Meanwhile, the criteria of the theories for review was almost similar with the previous studies, but the difference was on the quantity. The trend of the present research article was to apply the previous study of journal or proceeding more than the books or electronic book. It was also found in the object 1 . In fact, journal and proceeding give faster study development than hard book or electronic book. It was caused by the frequency of publication and the complex process of publishing a book. In this case, researchers still recommended the authors still applying the book especially for the grounded theory although the quantity should be fewer than journal or proceeding articles. The benefit was that the suggestion will be hard to be denied or refused by the readers or practitioners because it has strong basis. The other attention was to consider the allocation of information. The information was really intended to enlarge readers' knowledge [14], but the authors' information should be bigger than the information or knowledge that was given by the previous studies. It was caused that the main information was still the authors' research.

The third technique was the proposition of the improvement action that had been conducted by the writers or researchers. It was found in the article or object 2 . The implication of the technique was to emphasize the writers' successfulness to find, manage, and solve the weakness and lack in the research. The writers could give strong suggestion for the improvement concept because it had been proven effectively. This technique gives benefit of 
promoting a novelty that had been found. As the consequence, this technique needs valid process and result to support the suggestion. This technique could be developed to promote the novelty in order to introduce the researchers' identity. One study suggested indirectly that his research had been able to contribute to the literature on the potential value of the appropriate use of Web 2.0 in the educational settings [16]. The promotion of the finished-improvement program should be applied indirectly so that readers will not give negative assumption.

The fourth technique still refers to the object or article 2 . The suggestion technique was to propose the finding of the solution to solve problem of a process. The important notice is that the technique is only applicable for a research design whose purpose to improve process e.g. classroom action research. The potential benefit of the technique was to promote the whole article contents. One of the skills in academic writing was promoting the hypothesis [1]. In fact, the suggestion through promotion will be lack even meaningless when it does not bring any benefit for the readers or practitioners. In this context, the benefits were the benefits for readers and practitioners. In some cases, the researchers just stop giving the benefits for themselves. They assumed that after solving their scientific problem, it would had been finished totally. In fact, readers and practitioners always wait for the scientific and academic contribution. The proposition of the research benefit was actually an effective way to promote the research itself. One of the key points was the formulation or synthesis in the discussion. Readers who were searching the reference concern on looking the concept for their writing material. It does not matter whether the suggestion was proposed directly or indirectly, the matter was that how to make sure that the finding formula was scientific and free from plagiarism.

The fifth technique was the proposition of the research topic strengths through explaining the convenient process. It was found in the article or object 3 . The implication of the technique needs the arrangement of explanation in a sequence of chronological events. The writers had to explain the basic concept of the topic first. It also requires the comparison with previous study. The benefit of the technique was the finishing of two works simultaneously in which the writers could give suggestion and explains the research background in one occurrence. The other benefit was to make the article become more coherence because it connected the persuasive voice with the research background. The consequence was that the technique requires long explanation in the research background. The similar technique was also applied by one study that management of topic limitation and organization needs to be explained in the thesis statement directly [14]. Other study proposed the crucial rule of logical writing organization to make the coherence of writing in proposing the idea in one of the finding example [9]. It also happened when giving suggestion. In this finding, the presentation of chronological occurrence increased the possibility to suggest our concept or finding to readers. The convenient logical explanation ensured readers about the validity of the information.

The sixth technique was to emphasize the chronological event in the research method. It refers to the finding in the object or article 3 . In the method, it needs to explain in good sequence and coherence between the research design, instrument, and method of collecting and analyzing data which all of them must represent the effort to answer the research problem and objective in the background. The logical coherence of happening was a must requirement [9]. The coherence explanation in the method chapter could attract the readers' attention, even certain practitioners to be replicated the method concept. It could be an indirect suggestion to duplicate and follow the research concept. The benefit was that the authors could increase the text credibility because the research method was designed and carried out in the stratified system. It also helped readers to get understandable information. In this case, good explanation of coherence could attract the readers' attention and trust. One mistake that should 
not be done was repeating the explanation in high frequency. One example was when an author repeated information in one sub-chapter to the next sub-chapter. It could decrease the readers' trust.

The seventh technique was the proposition of the potential benefits of the research finding, result, or product in a specific area. The technique refers to the finding in the article or object 4 . The implication of the technique was to propose the logic and large possibility of the finding contribution for the social life and education practice. It also needs real comparison with the previous studies or the relevant similar study field. In the article, the writers proposed the benefits of using postmodified noun in the writing practice, then, it also needed to be compared with the writing practice whether based on the previous studies or curriculum concept. The consequence of the technique was the necessary of high effort to ensure the possibility of the benefit potential. In the persuasive writing study field, it was found that writing with context make students develop analysis when they wrote a reasonable paragraph and make readers give their expectation easier [14]. The suggestion of the potential benefit was easy to be applied because it serves a product to readers. They just need to take and apply it.

The eighth technique was to proposed the successfulness of the research product. The suggestion technique refers to the finding of the object or article 4 . The benefit of the technique was that the authors could also promote their product indirectly to the readers, moreover if the product was discussed by the readers in their text. On the other hand, the technique was recommended only for the research design whose purpose to produce something e.g. experimental research. The authors need to explain the product benefit to attract the readers' attention. The product must represent the value that never exists before so that it offers new paradigm. In order to apply this technique, the genre of the text must be determined before deciding the topic because the genre could give the schema of thinking to readers before deciding to read the text [11]. The product benefit should also be reflected in the title first. It was not recommended to encourage readers guessing the design. The benefit of the research must be based on the fact, not on the argumentation. It requires the field evidences of the benefits. The important notice was that the benefit contribution as intended to give assistance for the practitioner in the similar field, e.g. the benefit of an instrument of teaching vocabulary for English teachers.

The ninth technique was giving the direct recommendation of a problem solution based on an expert quotation. The finding refers to the article or object 5 . The technique was applied by proposing the direct quotation. The implication was that the writers must review the strengths of the quotation to ensure the readers about the valuable of the quotation. The benefit of the technique was to be the safest way for writers because the writers' position was just to review and present the expert quotation. As the consequence, the writers had to involve the grounded theory and the recent previous study. It will be very fragile not to involve the grounded theory. It was also found in the term of "evidential" that citation of others' writers' work provides credibility to the writers' writing [17]. When suggesting a thing by elaborating the writers' own idea combined with the previous study, it will give very high credibility impression. It gives the impression that the suggestion and recommendation had been prepared very well, not just taken for granted.

The tenth technique was to build logical argumentation by reviewing and connecting more than one theories or previous studies whose similar work schema. The suggestion technique refers to the object or article 5. The obstacle was to give the direct recommendation in the soft or hedge technique. The benefit of the technique was getting scientific impression because the argumentation was based on more than one previous study or theory. The 
consequence to apply the technique was that the authors must present the previous studies or theories which support to one another. In other hand, they must also differentiate directly their statement with the quotation. It was about the skill of building the cognitive concept strategy [2]. It does not persuade readers to believe, but it proposes and reviews the concept which could be accepted by the logical thinking system. It means the technique was not about personal felling, but it was about the strategy to build the system of logical work schema. If the technique is success, the readers will agree with the material directly. It is caused that the logical proposition cannot be debated anymore.

\section{Conclusions}

The ten techniques of giving suggestion based on Interpersonal meaning concept had good benefit potential. It was not about just persuading readers, but it tends to propose the logic and empiric discussion, presentation, and exploration. In this study, the novelty was that the researchers avoid giving the concept of manipulation to the readers' view point, but giving the better choice and perspective based on scientific fact and concept. The old concept of manipulating readers' perspective or encouraging reader to appreciate our idea needs to be avoided. The benefit of the ten techniques of giving suggestion will be also potential developed by the further researchers in both written and spoken study. 


\section{References}

[1] E. R. Daminova, V. V. Tarasova, and A. A. Kirpichnikova, "Academic Writing as a Key Component of Academic Literacy," Turkish Online J. Des. Art C ommunication, no. April, pp. 698-703, 2017.

[2] M. Brinkschulte, E. Grieshammer, and M.-E. Stoian, "Translingual Academic Writing at Internationalised Universities: Learning From Scholars," J. Acad. Writ., vol. 8, no. 2, pp. 150 160,2018

[3] M. E. Dehkordi and H. Allami, "Evidentiality in Academic Writing," Theory Pract. Lang. Stud., vol. 2, no. 9, pp. 1895-1904, 2012.

[4] I. Ofte, "English Academic Writing Proficiency in Higher Education: Facilitating the Transition from Metalinguistic Awareness to Metalinguistic Competence," Acta Didact. Norge, vol. 8, no. 2, pp. 1-15, 2014.

[5] Michael Derntl, "Basics of Research Paper Writing and Publishing," Int. J. Technol. Enhanc. Learn., vol. 6, no. 2, pp. 105-123, 2014.

[6] da F. bt A. Badiozaman, "I'm Getting There": an Investigation of Academic Writing Developments of Undergraduate Students in a Foreign Branch Campus in Malaysia," Issues Lang. Stud., vol. 6, no. 1, pp. 40-60, 2017.

[7] G. Patriotta, "Crafting Papers for Publication: Novelty and Convention in Academic Writing," J. Manag. Stud., vol. 54, no. 5, pp. 747-459, 2017.

[8] H. M. El-daly, "Cross-Cultural and Cognitive Variation in the Persuasive Writing of Arabic and Spanish Speakers: A Qualitative Analysis,” Int. J. Acad. Res. Bus. Soc. Sci., vol. 2, no. 7, pp. 51-81, 2012.

[9] Z. Pei, C. Zheng, M. Zhang, and F. Liu, "Critical Thinking and Argumentative Writing: Inspecting the Association among EFL Learners in China," English Lang. Teach., vol. 10, no. 10, pp. 31-42, 2017.

[10] B. R. Sugiarto, A. Sofwan, and D. Sutopo, "Mood Realization of the Learning Activities in the Grade VII English Textbook Published by the Ministry of Education and Culture," English Educ. J., vol. 5, no. 1, pp. 1-6, 2015.

[11] S. W. Fitriati and B. I. Ghasani, "An Appraisal Analysis of Critical Reviews Written by Undergraduate Students of English Language Education," in The 6th International Conference Proceedings October 2017, 2017, no. October, pp. 507-514.

[12] J. R. Martin and P. R. R. White, The Language of Evaluation Appraisal in English. New York: Palgrave Macmillan, 2005.

[13] R. E. Stake, Qualitative Research Studying How Things Work. New York: The Guilford Press, 2010.

[14] E. S. Wahyuni, "The Strategy of Using Persuasive Essay in English for Medical Academic Writing,” J. Sos. Hum., vol. 7, no. 1, pp. 1-19, 2017.

[15] P. Brett and D. Thomas, "Discovering Argument: Linking Literacy, Citizenship Education, and Persuasive Advocacy,” J. Soc. Sci. Educ., vol. 13, no. 4, pp. 66-77, 2014.

[16] O. H. Sayed, "Developing Business Management Students' Persuasive Writing Through Blogbased Peer-Feedback," English Lang. Teach., vol. 3, no. 3, pp. 54-66, 2010.

[17] H. Tan and W. B. Eng, "Metadiscourse Use in the Persuasive Writing of Malaysian Undergraduate Students," English Lang. Teach., vol. 7, no. 7, pp. 26-39, 2014. 